\title{
Correction to: How can potatoes be smartly cultivated with biochar as a soil nutrient amendment technique in Atlantic Canada?
}

\author{
Aitazaz A. Farooque ${ }^{1} \cdot$ Qamar Zaman $^{2} \cdot$ Farhat Abbas $^{1} \cdot$ Hafiz Mohkum Hammad $^{3} \cdot$ Bishnu Acharya $^{1} \cdot$ Travis Esau $^{2}$
}

Published online: 12 September 2020

(C) Saudi Society for Geosciences 2020

Correction to: Arabian Journal of Geosciences (2020) 13: 336 https://doi.org/10.1007/s12517-020-05337-3

The original version of this paper was published with error. Corresponding author requested to make a necessary correction in the spelling for the last name of the following co-author:

The correct name is: Travis Esau

Mistakenly spelled as: Travis Easu

Given in this article is the correct family name.

The online version of the original article can be found at https://oi.org/ $10.1007 / \mathrm{s} 12517-020-05337-3$

\footnotetext{
Aitazaz A. Farooque

afarooque@upei.ca

$\bowtie$ Farhat Abbas

fabbas@upei.ca

1 Faculty of Sustainable Design Engineering, University of Prince

Edward Island, Charlottetown, PEI C1A 4P3, Canada

2 Department of Engineering, Faculty of Agriculture, Dalhousie University, Truro, NS B2N 5E3, Canada

3 Department of Environmental Sciences, COMSATS University Islamabad, Vehari Campus, Vehari 61100, Pakistan
} 